\title{
Serum amyloid $A$ inhibits dendritic cell differentiation by suppressing GM-CSF receptor expression and signaling
}

\author{
Ji Cheol Kim ${ }^{1}$, Young Su Jung ${ }^{1}$, Ha Young Lee ${ }^{1}$, Joon Seong Park ${ }^{2}$ and Yoe-Sik Bae ${ }^{1,3}$
}

In this study, we report that an acute phase reactant, serum amyloid A (SAA), strongly inhibits dendritic cell differentiation induced by GM-CSF plus IL-4. SAA markedly decreased the expression of MHCII and CD11c. Moreover, SAA decreased cell surface GM-CSF receptor expression. SAA also decreased the expression of $P U .1$ and $C / E B P \alpha$, which play roles in the expression of GM-CSF receptor. This inhibitory response by SAA is partly mediated by the well-known SAA receptors, Toll-like receptor 2 and formyl peptide receptor 2 . Taken together, we suggest a novel insight into the inhibitory role of SAA in dendritic cell differentiation.

Experimental \& Molecular Medicine (2017) 49, e369; doi:10.1038/emm.2017.120; published online 25 August 2017

\section{INTRODUCTION}

Dendritic cells (DCs) are professional antigen-presenting cells of the mammalian immune system that play an essential role in the regulation of adaptive immune responses. ${ }^{1}$ The major function of DCs is to uptake and process antigens, and then to present them on the cell surface with major histocompatibility (MHC) complex to T cells. ${ }^{1}$ Because DCs are important players in interconnecting the innate and adaptive immune systems, the regulation of DC differentiation and maturation is of considerable importance., ${ }^{2,3}$ Previously, it was reported that DCs can be generated from mouse bone marrow cells by GM-CSF plus IL-4. ${ }^{4}$ Immature DCs express low levels of surface antigens, such as CD40, CD80 and CD86, and show high phagocytic activity. ${ }^{1}$ Diverse pathogen-derived molecules, including lipopolysaccharides (LPS), bacterial DNA and cytokines such as tumor necrosis factor- $\alpha$ (TNF- $\alpha$ ) elicit DC maturation, which then express high levels of surface antigens (CD40, CD80 and CD86) and have high antigenpresentation levels. ${ }^{1}$ Although many different molecules have been reported to regulate DC maturation, extracellular signals that negatively regulate DC differentiation have not been studied extensively.

Serum amyloid A (SAA) proteins are a family of apolipoproteins that are associated with high-density lipoprotein. ${ }^{5}$ SAA is known as a major acute-phase protein because it is released into circulation in response to pathogen infection or tissue injury, reaching approximately a 1000 -fold increase. ${ }^{6}$ SAA is mainly produced from the liver in response to a pro-inflammatory environment. ${ }^{7}$ Previously, SAA was reported to regulate diverse functional activities in lipid metabolism and in immune modulation. ${ }^{8}$ SAA influences high-density lipoprotein cholesterol metabolism by inhibiting receptor-mediated selective lipid uptake. ${ }^{9}$ It also decreases lipid biosynthesis. ${ }^{10}$ Regarding the immune modulatory functions of SAA, it induces matrix metalloproteinase production, elicits leukocyte chemotactic migration, upregulates adhesion molecule expression and induces cytokine synthesis. ${ }^{11-13}$ Regarding the target receptors of SAA, several different cell surface receptors, including formyl peptide receptor (FPR)2, Toll-like receptor (TLR)4, TLR2 and P2X7, have been reported to mediate specific cellular responses induced by SAA. ${ }^{12,14-16}$ However, the roles of SAA on DC differentiation have not yet been investigated. Here we attempted to determine whether SAA affects DC differentiation in mouse bone marrow cells under GM-CSF plus IL-4 stimulation. We also examined target receptors and the mechanism of action involved in the regulation of DC differentiation by SAA.

\section{MATERIALS AND METHODS}

Materials

Six- to eight-week-old male C57BL/6 mice were purchased from Daehan Bio Link (Eumseong, Korea). The TLR2-deficient mice were

\footnotetext{
${ }^{1}$ Department of Biological Sciences, Sungkyunkwan University, Suwon, Republic of Korea; ${ }^{2}$ Department of Hematology-Oncology, Ajou University School of Medicine, Suwon, Republic of Korea and ${ }^{3}$ Department of Health Sciences and Technology, SAlHST, Sungkyunkwan University, Seoul, Republic of Korea Correspondence: Professor Y-S Bae, Department of Biological Sciences, Sungkyunkwan University, Suwon 16419, Republic of Korea.

E-mail: yoesik@skku.edu

Received 3 January 2017; revised 7 March 2017; accepted 9 March 2017
} 
donated by Professor Jong-Hwan Park (Chonnam National University, Gwangju, Korea). Human recombinant SAA, murine recombinant GM-CSF and murine recombinant IL-4 were purchased from Peprotech (Rocky Hill, NJ, USA). Pam3CSK4 was purchased from Invivogen (San Diego, CA, USA). LPS was purchased from Sigma-Aldrich (St Louis, MO, USA). WRWWWW (WRW4) was synthesized from Anygen (Gwangju, Korea). Antibodies against phospho-STAT5, STAT5 and actin were purchased from Cell Signaling Technology (Beverly, MA, USA). RPMI 1640 was purchased from Welgene (Gyeongsan, Korea). Anti-mouse CD11b, CD11c, MHCII and F4/80 antibodies were obtained from eBioscience (San Diego, CA, USA). Anti-mouse GM-CSF receptor (GM-CSFR) $\alpha$ was purchased from R\&D Systems (Minneapolis, MN, USA).

\section{DC differentiation}

Mouse bone marrow-derived DCs were generated from mouse bone marrow cells according to a previous report ${ }^{17}$ with some modifications. Briefly, mouse bone marrow cells were isolated from the femurs and tibiae of 6-8-week-old male C57BL/6 mice and treated with ACK lysis buffer (Gibco, Carlsbad, CA, USA) to remove red blood cells. The cells were washed and cultured in 10\% FBS containing RPMI 1640 media with $20 \mathrm{ng} \mathrm{ml}^{-1}$ mGM-CSF and $2 \mathrm{ng} \mathrm{ml}^{-1}$ mIL-4. After 2 days, non-adherent cells were washed and refreshed with $2 \mathrm{ml}$ of fresh complete medium containing mGM-CSF and mIL-4. On day 4, $1 \mathrm{ml}$ of fresh complete medium containing mGM-CSF and mIL-4 was added to the culture. Cells were harvested for the experiment on day 6. SAA was added to the culture media each time the medium was changed.

\section{Quantitative real-time RT-PCR}

Quantitative PCR was performed using the Rotor-Gene SYBR Green PCR kit (Qiagen, Hilden, Germany), The primer sequences used include RelB: forward, 5'-GTTCCAGTGACCTCTCTTCC-3', reverse, $5^{\prime}$-CCAAAGCCGTTCTCCTTAATGTA-3' ${ }^{\prime}{ }^{18}$ Maf forward, reverse, ${ }^{18}$ GM-CSFR $\alpha$ : forward, 5'-CTGATGTCATGAAGCGATGC-3', reverse, 5'-TCACGGTGACATCAATGTCG-3', ${ }^{\prime}$ PU.1: forward, 5'-GATGG AGAAGCTGATGGCTTGG-3', reverse, 5'-TTCTTCACCTCGCCTG TCTTGC-3' ${ }^{\prime 20}$ C/EBP $\alpha$ : forward, 5'-TGGACAAGAACAGCAACG AGTAC-3', reverse, 5'-GCAGTTGCCCATGGCCTTGAC-3'21 and GAPDH: forward, 5'-TCCACCACCCTGTTGCTGTA-3', reverse, 5'-AATGTGTCCGTCGTGGATCT-3'. The rotor-gene Q (2plex on PC) instrument (Qiagen) was programmed as follows: $95^{\circ} \mathrm{C}$ for $10 \mathrm{~min}$, then 50 cycles of $95^{\circ} \mathrm{C}$ for $10 \mathrm{~s}, 60^{\circ} \mathrm{C}$ for $15 \mathrm{~s}$ and $72{ }^{\circ} \mathrm{C}$ for $20 \mathrm{~s}$. The data were analyzed using rotor-gene $\mathrm{Q}$ series software through the delta-delta CT method. ${ }^{22}$

\section{Western blot assay}

Mouse bone marrow cells were stimulated with GM-CSF $\left(20 \mathrm{ng} \mathrm{ml}^{-1}\right)$ for various periods of time, and then the cells were lysed in lysis buffer (20 mм HEPES ( $\mathrm{pH} 7.2$ ), 10\% glycerol, $150 \mathrm{~mm} \mathrm{NaCl}, 1 \%$ Triton $\mathrm{X}-100,50 \mathrm{~mm} \mathrm{NaF}, 1 \mathrm{~mm} \mathrm{Na}_{3} \mathrm{VO}_{4}, 10 \mu \mathrm{g} \mathrm{ml}^{-1}$ leupeptin, $10 \mu \mathrm{g} \mathrm{ml}-1$ a

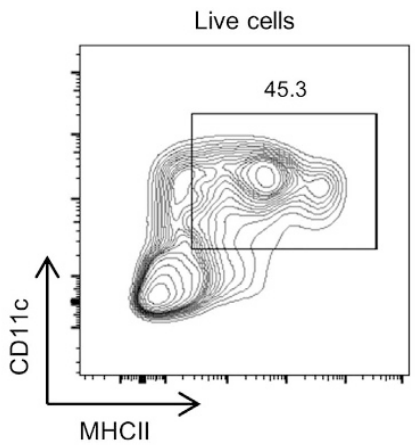

b

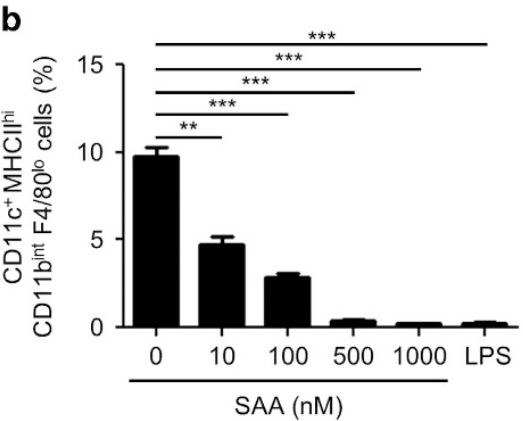

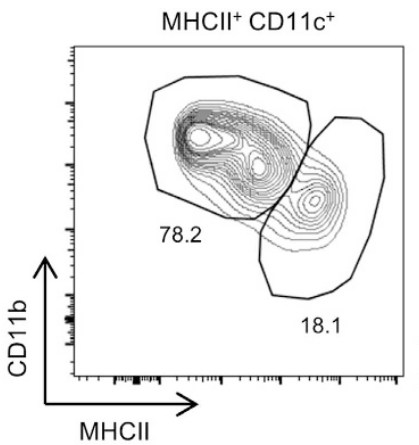

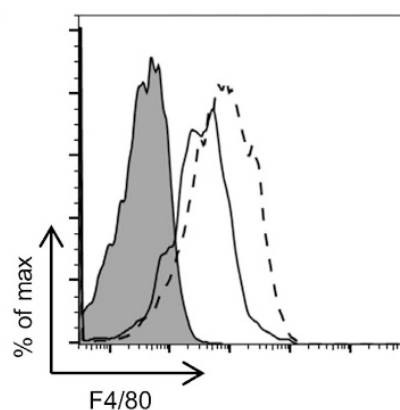

CD11C+MHCII ${ }^{\text {hi }} C D 11 b^{\text {int }}$
$-\boldsymbol{-}$ - CD11C+MHCII $C D 11 b^{\text {hi }}$ c

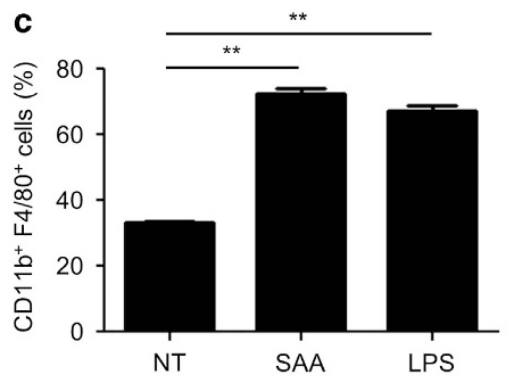

d

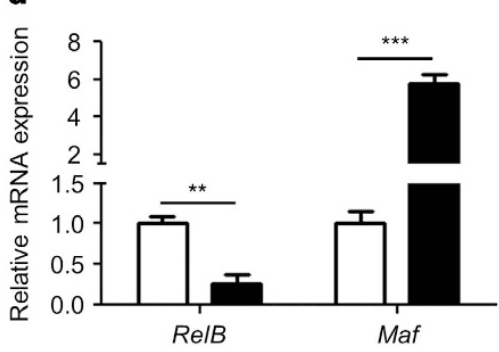

Figure 1 Serum amyloid A (SAA) inhibits DC differentiation induced by GM-CSF plus IL-4. (a) Flow cytometric gating strategy of DCs from cultures at day 6 . Solid line, $\mathrm{CD} 11 \mathrm{C}^{+} \mathrm{MHCI}{ }^{\text {hi }} \mathrm{CD} 11 \mathrm{~b}^{\text {int }}$ population; dashed line, $\mathrm{CD} 11 \mathrm{C}^{+} \mathrm{MHCI} \mathrm{I}^{\mathrm{lo}} \mathrm{CD} 11 \mathrm{~b}^{\text {hi }}$ population; shaded, isotypes control. (b) Percentage of the CD11 $\mathrm{c}^{+} \mathrm{MHCI} \mathrm{I}^{\text {hi }} \mathrm{CD} 11 \mathrm{~b}^{\text {int }}$ population stimulated with a vehicle (DW), several concentrations of SAA or LPS (100 $\mathrm{ng} \mathrm{ml}^{-1}$ ) in the presence of GM-CSF $\left(20 \mathrm{ng} \mathrm{ml}^{-1}\right.$ ) plus IL-4 $\left(2 \mathrm{ng} \mathrm{ml}^{-1}\right)$ for 6 days. (c) Percentage of CD11 b+F4/80+ cells stimulated with a vehicle and SAA (500 nm) with GM-CSF plus IL-4 for 6 days. (d) RelB and Maf mRNA expression levels in vehicle or SAA (500 nm)-treated cells with GM-CSF plus IL-4 for 6 days were analyzed by real-time polymerase chain reaction (qPCR). The results shown are representative of three independent experiments (a). Data are the mean \pm s.e. of three independent experiments performed in duplicate (b-d). ${ }^{* *} P<0.01$ and ${ }^{* *} P<0.001$. 

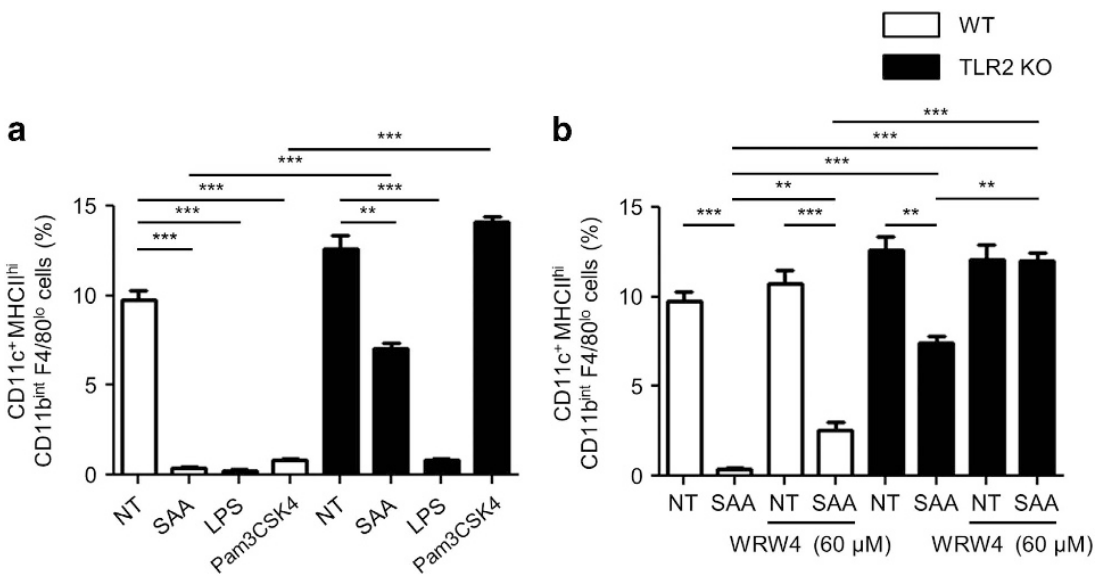

Figure 2 The inhibitory effect of serum amyloid A (SAA) on DC differentiation is mediated by TLR2 and FPR2. (a) Mouse bone marrow cells isolated from wild-type or TLR2-deficient mice were stimulated with the vehicle (DW), SAA (500 nm), LPS (100 ng ml-1) or Pam3CSK4 (100 ng ml-1) in the presence of GM-CSF $\left(20 \mathrm{ng} \mathrm{ml}^{-1}\right)$ plus IL-4 $\left(2 \mathrm{ng} \mathrm{ml}^{-1}\right)$ for 6 days. (b) Mouse bone marrow cells isolated from wild-type or TLR2-deficient mice were pre-incubated with vehicle (DMSO) or WRW4 (60 $\mu \mathrm{m})$ for $30 \mathrm{~min}$, and the cells were then stimulated with vehicle or SAA (500 nm) in the presence of GM-CSF (20 ng ml-1) plus IL-4 ( $2 \mathrm{ng} \mathrm{ml}^{-1}$ ) for 6 days. The percentage of DCs was analyzed by flow cytometry. The results shown are representative of three independent experiments $(\mathbf{a}, \mathbf{b})$. Data are mean $\pm \mathrm{s}$.e. of three independent experiments performed in duplicate $(\mathbf{a}, \mathbf{b}) .{ }^{* *} P<0.01$ and ${ }^{* * *} P<0.001$.

aprotinin and $1 \mathrm{~mm}$ phenylmethylsulfonyl fluoride (PMSF)). Detergent-insoluble materials were pelleted by centrifugation (12 $000 \mathrm{~g}$ for $10 \mathrm{~min}$ at $4^{\circ} \mathrm{C}$ ) and the soluble supernatant fraction was removed and used immediately. Western blot analysis was conducted as described previously. ${ }^{23}$ Briefly, proteins were separated on $10 \%$ SDS-polyacrylamide gels and blotted onto a nitrocellulose membrane. Subsequently, the membranes were incubated with specific 1:5000 diluted goat anti-rabbit IgG antibody combined with horseradish peroxidase, and antigen-antibody complexes were visualized by enhanced chemiluminescence.

\section{Flow cytometry}

Differentiated mouse bone marrow cells were incubated with anti-murine CD16/32 to block Fc receptor-mediated antibody binding for $20 \mathrm{~min}$ on ice. The cells were then incubated with anti-mouse $\mathrm{CD} 11 \mathrm{~b}$, anti-mouse CD11c, anti-mouse MHCII, anti-mouse F4/80 and anti-mouse GM-CSFR $\alpha$. A FACSCanto II (BD Bioscience, San Jose, CA, USA) was used for detection of CD11b, CD11c, MHCII, F4/80 and GM-CSFR $\alpha$ surface expression.

\section{Statistical analysis}

The results were evaluated with GraphPad prism software (GraphPad Software, La Jolla, CA, USA). Statistical analysis was performed using the one-way analysis of variance test followed by the Student's $t$-test. All results are expressed as the mean \pm s.e. A $P$-value $<0.05$ was considered statistically significant.

\section{RESULTS}

SAA inhibits DC differentiation from mouse bone marrow cells

To determine whether SAA affects DC differentiation, we stimulated mouse bone marrow cells with SAA in the presence of GM-CSF plus IL-4. Incubation of mouse bone marrow cells with GM-CSF plus IL-4 strongly induces DC differentiation. DCs were gated as the CD $11 c^{+}$
MHCII ${ }^{\text {hi }} \mathrm{CD} 11 \mathrm{~b}^{\text {int }}$ population, and these cells expressed low levels of F4/80 (Figure 1a). ${ }^{18,24}$ The addition of several different SAA concentrations inhibited the DC differentiation in a concentration-dependent manner (Figure 1b). The addition of 500-1000 nM SAA markedly inhibited DC differentiation (Figure 1b). However, the percentage of $\mathrm{CD} 11 \mathrm{~b}^{+} \mathrm{F} 4 / 80^{+}$cells was increased by $500 \mathrm{~nm}$ SAA (Figure 1c). LPS also markedly inhibited DC differentiation and increased the $\mathrm{CD} 11 \mathrm{~b}^{+} \mathrm{F} 4 / 80^{+}$ population (Figures $1 \mathrm{~b}$ and $\mathrm{c}){ }^{25}$ In addition, the RelB mRNA expression (a transcription factor of DC) ${ }^{26}$ was significantly reduced by SAA (Figure 1d). In contrast, the Maf mRNA expression (macrophage marker gene) ${ }^{26}$ was markedly increased by SAA (Figure 1d).

\section{TLR2 and FPR2 are involved in the SAA-induced inhibitory effects on DC differentiation}

As TLR2 is known as an important TLR target molecule for $\mathrm{SAA},{ }^{15}$ we examined the roles of TLR2 in the SAA-induced inhibitory effects on DC differentiation. The SAA-induced inhibitory effect on DC differentiation was significantly reversed in TLR2-deficient mice compared with control wild-type mice (Figure 2a). We also found that a well-known TLR2 agonist, Pam3CSK4, inhibited DC differentiation (Figure 2a). The inhibitory effects of Pam3CSK4 on DC differentiation were reversed compared with the TLR2-deficient mice (Figure 2a). However, the LPS-induced inhibitory effect on DC differentiation was not affected by the TLR2 deficiency (Figure 2a). The above results suggest that SAA inhibits DC differentiation via a TLR2-dependent pathway.

Previously, SAA was reported to act on an important chemoattractant G-protein-coupled receptor, FPR2. ${ }^{12}$ To test the role of FPR2 on the inhibitory effect of DC differentiation, we incubated mouse bone marrow cells with WRW4 (an FPR2 

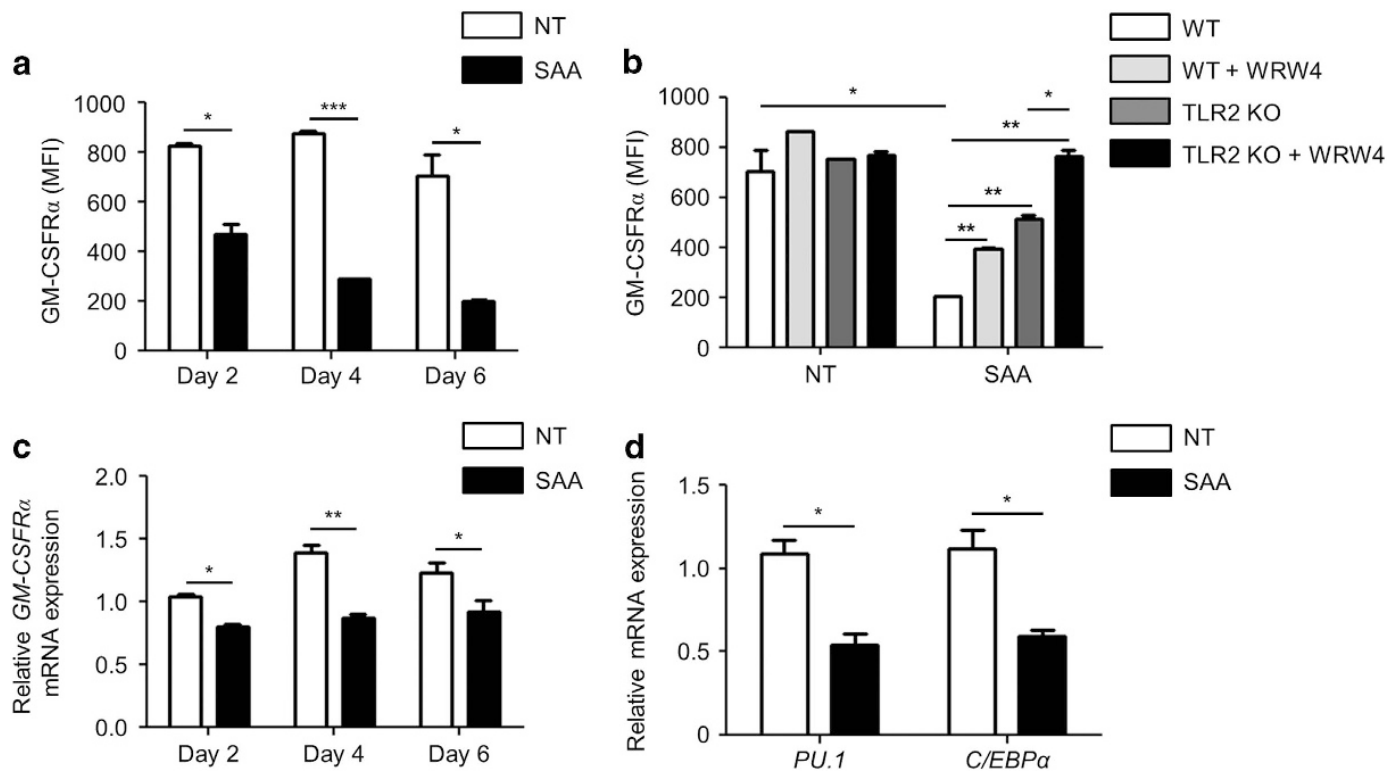

Figure 3 Serum amyloid A (SAA) blocks GM-CSFR expression by inhibiting PU.1 and C/EBP $\alpha$ levels. (a) Mouse bone marrow cells were stimulated with GM-CSF plus IL-4 for 2, 4 or 6 days in the absence or presence of SAA (500 nM). (b) Mouse bone marrow cells isolated from wild-type or TLR2-deficient mice were pre-incubated with vehicle (DMSO) or WRW4 (60 $\mu \mathrm{m})$ for 30 min, and the cells were then

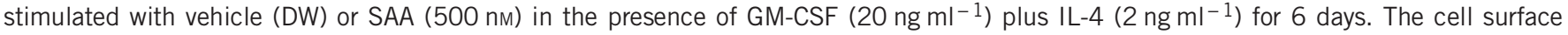
GM-CSFR expression levels were determined by flow cytometry using an anti-GM-CSFR $\alpha$ antibody (a, b). (c) Mouse bone marrow cells were stimulated with vehicle or SAA (500 nm) in the presence of GM-CSF (20 ng ml-1) plus IL-4 (2 $\left.\mathrm{ng} \mathrm{ml}^{-1}\right)$ for 2, 4 or 6 days. The GM-CSFR mRNA levels were analyzed by qPCR. (d) Mouse bone marrow cells were stimulated with vehicle or SAA (500 nm) in the presence of GM-CSF $\left(20 \mathrm{ng} \mathrm{ml}^{-1}\right)$ plus IL-4 $\left(2 \mathrm{ng} \mathrm{ml}^{-1}\right)$ for 2 days. PU.1 and C/EBP $\alpha \mathrm{mRNA}$ levels were analyzed by qPCR. Data are mean \pm s.e. of three independent experiments performed in duplicate (a-d). ${ }^{*} P<0.05,{ }^{*} P<0.01$ and ${ }^{* * *} P<0.001$.

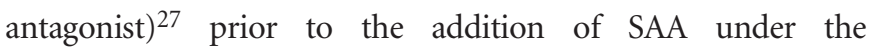
DC differentiation inducing cytokines, GM-CSF plus IL-4. The addition of WRW4 partially reversed the inhibitory effect of SAA on DC differentiation induced by GM-CSF plus IL-4 (Figure 2b). As the SAA-induced inhibitory effect on DC differentiation was partly mediated by TLR2, we tested the effect of WRW4 on DC differentiation in TLR2-deficient mice. The inhibitory effect of SAA on DC differentiation was completely reversed by WRW4 in TLR2-deficient mice (Figure 2b). The results suggest that SAA inhibits DC differentiation via both FPR2 and TLR2.

\section{SAA decreases GM-CSFR expression by inhibiting PU.1 and C/EBP $\alpha$ expression}

GM-CSFR is a receptor for GM-CSF and is crucial for DC differentiation. ${ }^{2}$ As we found that SAA inhibits DC differentiation induced by GM-CSF plus IL-4 from mouse bone marrow cells (Figure 1), we attempted to determine whether SAA affects the GM-CSFR expression in these cells. Interestingly, the addition of SAA in mouse bone marrow cells decreased the GM-CSFR surface expression (Figure 3a). The inhibitory effects of SAA on GM-CSFR expression were continued from days 2 to 6 during DC differentiation (Figure 3a). As the SAA-induced inhibitory effect on DC differentiation was mediated by TLR2 and FPR2 (Figure 2), we examined whether the two receptors play a role in the
SAA-induced decrease of GM-CSFR on the cell surface. WRW4 partially reversed the SAA-induced inhibitory effect on the GM-CSFR expression (Figure 3b). The inhibitory effect of SAA on the GM-CSFR expression was also partly reversed in TLR2-deficient mice (Figure 3b). Moreover, WRW4 treatment in TLR2-deficient mice-derived bone marrow cells completely reversed the inhibitory effect of SAA on the GM-CSFR expression (Figure 3b).

We then attempted to determine whether SAA decreases GM-CSFR expression at the mRNA level. The GM-CSFR mRNA expression was decreased by SAA in mouse bone marrow cells (Figure 3c). The inhibitory effects of SAA on the GM-CSFR mRNA expression continued from days 2 to 6 during DC differentiation (Figure 3c). The results suggest that the SAA-induced inhibitory effect on GM-CSFR expression is mediated at the mRNA level. To understand the mechanism involved in the inhibitory effects of SAA on GM-CSFR expression, we examined the transcription factors involved in GM-CSFR expression ${ }^{28}$ and the differentiation of certain hematopoietic cells. ${ }^{29-32}$ In a previous report, PU.1 was reported to be a crucial transcription factor for DC development by playing a key role in GM-CSF-induced DC generation from DC progenitor cells. ${ }^{30,31}$ In this study, we found that the bone marrow cell stimulation with SAA decreased the PU.1 mRNA level expression (Figure 3d). Another previous study demonstrated that C/EBP $\alpha$ plays an important role in the early stages of DC differentiation. ${ }^{32}$ SAA 
a

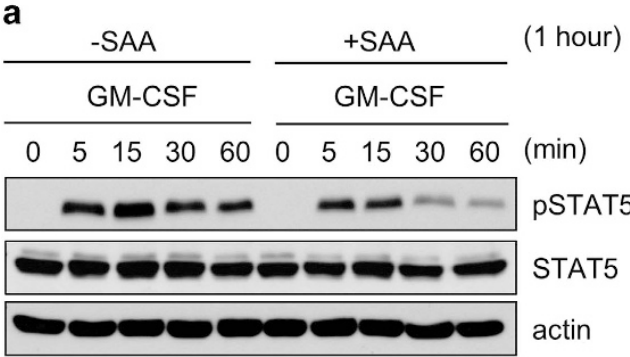

b

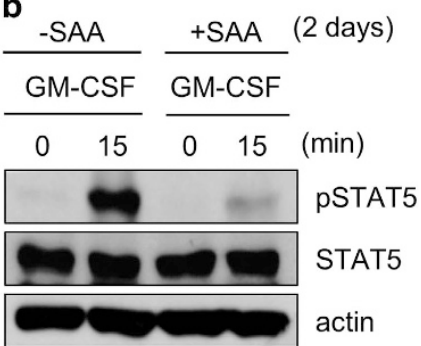

Figure 4 Serum amyloid A (SAA) inhibits GM-CSF-induced STAT5 phosphorylation. (a) Mouse bone marrow cells were pre-incubated with vehicle (DW) or SAA (500 nm) for $1 \mathrm{~h}$ and subsequently stimulated with GM-CSF $\left(20 \mathrm{ng} \mathrm{ml}^{-1}\right.$ ) for $0,5,15,30$ and 60 min. Phosphorylated STAT5 levels were measured by Western blot analysis with anti-phospho-STAT5 antibody. (b) Mouse bone marrow cells were stimulated with GM-CSF $\left(20 \mathrm{ng} \mathrm{ml}^{-1}\right)$ plus IL-4 $\left(2 \mathrm{ng} \mathrm{ml}^{-1}\right)$ for 2 days in the absence or presence of SAA (500 nm). Bone marrow cells were harvested and washed with cold PBS and then restimulated with GM-CSF $\left(20 \mathrm{ng} \mathrm{ml}^{-1}\right)$ for 15 min. Phosphorylated STAT5 levels were measured by Western blot analysis with an anti-phospho-STAT5 antibody. The results shown are representative of three independent experiments (a, b).

treatment also strongly decreased the C/EBP $\alpha$ mRNA levels (Figure 3d). The results suggest that SAA may suppress DC differentiation by decreasing these two important transcription factors, which are required for the GM-CSFR expression and DC development.

\section{SAA inhibits GM-CSF-stimulated signaling in mouse bone marrow cells}

The activation of GM-CSFR by GM-CSF induces STAT5 phosphorylation, which is important for the mediation of DC differentiation. ${ }^{2}$ Because SAA inhibited DC differentiation, we tested whether SAA affect GM-CSF-induced signaling by comparing STAT5 phosphorylation in response to GM-CSF in the absence or presence of SAA in bone marrow cells. The stimulation of mouse bone marrow cells with GM-CSF elicits STAT5 pathway activation, resulting in the STAT5 phosphorylation in a time-dependent manner (Figure 4a). The addition of SAA $(500 \mathrm{~nm})$ prior to GM-CSF markedly decreased the STAT5 phosphorylation (Figure 4a). As the addition of SAA decreased GM-CSFR expression (Figure 3), we examined whether reduced GM-CSFR affects STAT5 phosphorylation in response to GM-CSF. SAA that was added to bone marrow cells markedly decreased STAT5 phosphorylation in response to GM-CSF compared with vehicle treated cells. (Figure $4 \mathrm{~b}$ ). These results suggest that SAA may block GM-CSF-induced STAT5 activation via decreased GM-CSFR expression.

\section{DISCUSSION}

Although positive signals, including GM-CSF or GM-CSF plus IL-4, that induce DC differentiation have been extensively studied, extracellular signals that negatively regulate DC differentiation have not yet been clearly investigated. In this study, we demonstrate that SAA, a well-known endogenous acute phase reactant, inhibits DC differentiation from mouse bone marrow cells in response to GM-CSF plus IL-4, suggesting it plays a novel functional role in DC differentiation.
For the target receptors involved in the inhibitory effects of SAA on DC differentiation, we demonstrate that the SAA-induced inhibitory effects on DC differentiation in response to GM-CSF were partly reversed from TLR2deficient mice and FPR2 antagonist-treated bone marrow cells (Figure 2). The results suggest that at least two different receptors for SAA, TLR2 and FPR2, play roles in the inhibition. Regarding the mechanism of action of the inhibitory effect of SAA on GM-CSF-induced DC differentiation, we found that stimulation of mouse bone marrow cells with SAA decreases the surface expression of GM-CSFR on mouse bone marrow cells (Figure 3). The SAA-induced decrease of GM-CSFR on mouse bone marrow cells was also partly affected by TLR2 deficiency or by an FPR2 antagonist (Figure 3b). The above results indicate that SAA blocks DC differentiation by decreasing GM-CSFR expression through both TLR2 and FPR2.

Because SAA also decreased the expression of GM-CSFR mRNA in the cells (Figure 3c), the SAA-induced decrease of GM-CSFR was mediated at the mRNA level. The expression of GM-CSFR is regulated by two important transcription factors, PU.1 and $\mathrm{C} / \mathrm{EBP} \alpha$, which play key roles in DC differentiation. ${ }^{28-32}$ We found that SAA decreased the expression of $P U .1$ and $C / E B P \alpha$ in bone marrow cells (Figure 3d). In this study, we also found that the stimulation of bone marrow cells with SAA markedly inhibited GM-CSF-stimulated signaling, resulting in a decrease in STAT5 phosphorylation (Figure 4). As intracellular signaling, including STAT5, mediates the expression of PU.1 and C/EBP $\alpha$ in bone marrow cells, ${ }^{33-35}$ the inhibitory effect of SAA on the DC differentiation can be initially triggered by blocking the GM-CSF signaling in bone marrow cells. Blocking GM-CSF signaling subsequently elicits a decrease in GM-CSFR expression, resulting in the inhibition of DC differentiation.

SAA levels increase during the pathological processes of several infectious or inflammatory diseases. ${ }^{6,7,36,37}$ Elevated levels of SAA can recruit some inflammatory cells, including 
neutrophils, monocytes and endothelial cells. ${ }^{12,38}$ In this study, we demonstrate that SAA inhibits DC differentiation from mouse bone marrow cells. Considering that DC plays a key role in the initiation of immune responses against infection or tissue injury, ${ }^{1-3}$ our results suggest that increased SAA levels during infection or injury may show an inhibitory effect to reduce inflammatory responses to homeostasis. As SAA is mainly produced from hepatocytes, our results also suggest a possible negative feedback relationship between liver and bone marrow, where SAA mediates a crucial role by inhibiting DC differentiation.

In conclusion, we have demonstrated in this study that SAA, an acute phase reactant, strongly inhibits DC differentiation from bone marrow cells by decreasing GM-CSFR expression through two important cell surface receptors, TLR2 and FPR2. Our results suggest that SAA and its receptors (TLR2 and FPR2) can be regarded as targets to control human disorders in which DC mediates the pathological process.

\section{CONFLICT OF INTEREST}

The authors declare no conflict of interest.

\section{ACKNOWLEDGEMENTS}

This work was supported by Basic Science Research Program through the National Research Foundation of Korea (NRF) funded by the Ministry of Science, ICT and future Planning (NRF-2015R1A2A1A10 054567).

1 Banchereau J, Briere F, Caux C, Davoust J, Lebecque S, Liu YJ et al. Immunobiology of dendritic cells. Annu Rev Immunol 2000; 18: 767-811.

2 van de Laar L, Coffer PJ, Woltman AM. Regulation of dendritic cell development by GM-CSF: molecular control and implications for immune homeostasis and therapy. Blood 2012; 119: 3383-3393.

3 Palucka K, Banchereau J. Cancer immunotherapy via dendritic cells. Nat Rev Cancer 2012; 12: 265-277.

4 Xu Y, Zhan Y, Lew AM, Naik SH, Kershaw MH. Differential development of murine dendritic cells by GM-CSF versus Flt3 ligand has implications for inflammation and trafficking. J Immunol 2007; 179: 7577-7584.

5 Benditt EP, Eriksen N. Amyloid protein SAA is associated with high density lipoprotein from human serum. Proc Natl Acad Sci USA 1977; 74: 4025-4028.

6 Gabay C, Kushner I. Acute-phase proteins and other systemic responses to inflammation. N Engl J Med 1999; 340: 448-454.

7 Jensen LE, Whitehead AS. Regulation of serum amyloid A protein expression during the acute-phase response. Biochem J 1998; 334: 489-503.

8 Upragarin N, Landman WJ, Gaastra W, Gruys E. Extrahepatic production of acute phase serum amyloid A. Histol Histopathol 2005; 20: 1295-1307.

9 Cai L, de Beer MC, de Beer FC, van der Westhuyzen DR. Serum amyloid A is a ligand for scavenger receptor class B type $\mathrm{I}$ and inhibits high density lipoprotein binding and selective lipid uptake. J Biol Chem 2005; 280: 2954-2961.

10 Schreiber BM, Veverbrants M, Fine RE, Blusztajn JK, Salmona M, Patel A et al. Apolipoprotein serum amyloid A down-regulates smooth-muscle cell lipid biosynthesis. Biochem J 1999; 344: 7-13.

11 Lee HY, Kim MK, Park KS, Bae YH, Yun J, Park JI et al. Serum amyloid A stimulates matrix-metalloproteinase-9 upregulation via formyl peptide receptor like-1-mediated signaling in human monocytic cells. Biochem Biophys Res Commun 2005; 330: 989-998.

12 Su SB, Gong W, Gao JL, Shen W, Murphy PM, Oppenheim JJ. A seven-transmembrane, $G$ protein-coupled receptor, FPRL1, mediates the chemotactic activity of serum amyloid $A$ for human phagocytic cells. J Exp Med 1999; 189: 395-402.
13 Patel H, Fellowes R, Coade S, Woo P. Human serum amyloid A has cytokine-like properties. Scand J Immunol 1998; 48: 410-418.

14 Sandri S, Rodriguez D, Gomes E, Monteiro HP, Russo M, Campa A. Is serum amyloid A an endogenous TLR4 agonist? J Leukoc Biol 2008; 83: 1174-1180.

15 He RL, Zhou J, Hanson CZ, Chen J, Cheng N, Ye RD. Serum amyloid A induces G-CSF expression and neutrophilia via Toll-like receptor 2. Blood 2009; 113: 429-437.

16 Niemi K, Teirila L, Lappalainen J, Rajamaki K, Baumann MH, Öörni K et al. Serum amyloid A activates the NLRP3 inflammasome via P2X7 receptor and a cathepsin B-sensitive pathway. J Immunol 2011; 186: 6119-6128.

17 Miah MA, Yoon CH, Kim J, Jang J, Seong YR, Bae YS. CISH is induced during DC development and regulates DC-mediated CTL activation. Eur J Immunol 2012; 42: 58-68.

18 Na YR, Jung D, Gu GJ, Seok SH. GM-CSF grown bone marrow derived cells are composed of phenotypically different dendritic cells and macrophages. Mol Cells 2016; 39: 734-741.

19 Yamada T, Abe M, Higashi T, Yamamoto H, Kihara-Negishi F, Sakurai $T$ et al. Lineage switch induced by overexpression of Ets family transcription factor PU.1 in murine erythroleukemia cells. Blood 2001; 97: 2300-2307.

20 Ushmorov A, Leithäuser F, Sakk O, Weinhaüsel A, Popov SW, Möller P. Epigenetic processes play a major role in B-cell-specific gene silencing in classical Hodgkin lymphoma. Blood 2006; 107: 2493-2500.

21 Sandhir R, Berman NE. Age-dependent response of CCAAT/enhancer binding proteins following traumatic brain injury in mice. Neurochem Int 2010; 56: 188-193.

22 Livak KJ, Schmittgen TD. Analysis of relative gene expression data using real-time quantitative PCR and the 2(-delta delta $\mathrm{C}(\mathrm{T})$ ) method. Methods 2001; 25: 402-408.

23 Lee HY, Lee SY, Kim SD, Shim JW, Kim HJ, Jung YS. Sphingosylphosphorylcholine stimulates CCL2 production from human umbilical vein endothelial cells. J Immunol 2011; 186: 4347-4353.

24 Helft J, Böttcher J, Chakravarty P, Zelenay S, Huotari J, Schraml BU et al. GM-CSF mouse bone marrow cultures comprise a heterogeneous population of $\mathrm{CD} 11 \mathrm{c}(+) \mathrm{MHClI}(+)$ macrophages and dendritic cells. Immunity 2015; 42: 1197-1211.

25 Bartz H, Avalos NM, Baetz A, Heeg K, Dalpke AH. Involvement of suppressors of cytokine signaling in toll-like receptor-mediated block of dendritic cell differentiation. Blood 2006; 108: 4102-4108.

26 Egawa M, Mukai K, Yoshikawa S, Iki M, Mukaida N, Kawano Y et al. Inflammatory monocytes recruited to allergic skin acquire an anti-inflammatory M2 phenotype via basophil-derived interleukin-4. Immunity 2013; 38: 570-580.

27 Bae YS, Lee HY, Jo EJ, Kim JI, Kang HK, Ye RD et al. Identification of peptides that antagonize formyl peptide receptor-like 1-mediated signaling. J Immunol 2004; 173: 607-614.

28 Tenen DG, Hromas R, Licht JD, Zhang DE. Transcription factors, normal myeloid development, and leukemia. Blood 1997; 90: 489-519.

29 Hohaus S, Petrovick MS, Voso MT, Sun Z, Zhang DE, Tenen DG. PU.1 (Spi-1) and C/EBP alpha regulate expression of the granulocytemacrophage colony-stimulating factor receptor alpha gene. Mol Cell Biol 1995; 15: 5830-5845.

30 DeKoter RP, Walsh JC, Singh H. PU.1 regulates both cytokine-dependent proliferation and differentiation of granulocyte/macrophage progenitors. EMBO J 1998; 17: 4456-4468.

31 Carotta S, Dakic A, D'Amico A, Pang SH, Greig KT, Nutt SL et al. The transcription factor PU.1 controls dendritic cell development and Flt3 cytokine receptor expression in a dose-dependent manner. Immunity 2010; 32: 628-641.

32 Welner RS, Bararia D, Amabile G, Czibere A, Benoukraf T, Bach C et al. $\mathrm{C} / \mathrm{EBP} \alpha$ is required for development of dendritic cell progenitors. Blood 2013; 121: 4073-4081.

33 Voso MT, Burn TC, Wulf G, Lim B, Leone G, Tenen DG. Inhibition of hematopoiesis by competitive binding of transcription factor PU.1. Proc Natl Acad Sci USA 1994; 91: 7932-7936.

34 Shibata Y, Berclaz PY, Chroneos ZC, Yoshida M, Whitsett JA, Trapnell BC. GM-CSF regulates alveolar macrophage differentiation and innate immunity in the lung through PU.1. Immunity 2001; 15: 557-567.

35 Stewart WC, Morrison RF, Young SL, Stephens JM. Regulation of signal transducers and activators of transcription (STATs) by effectors of adipogenesis: coordinate regulation of STATs $1,5 \mathrm{~A}$, and 5B with peroxisome 
proliferator-activated receptor-gamma and C/AAAT enhancer binding protein-alpha. Biochim Biophys Acta 1999; 1452: 188-196.

36 Chambers RE, Stross P, Barry RE, Whicher JT. Serum amyloid A protein compared with C-reactive protein, alpha 1-antichymotrypsin and alpha 1acid glycoprotein as a monitor of inflammatory bowel disease. Eur J Clin Invest 1987; 17: 460-467.

37 Kumon Y, Suehiro T, Hashimoto K, Nakatani K, Sipe JD. Local expression of acute phase serum amyloid A mRNA in rheumatoid arthritis synovial tissue and cells. J Rheumatol 1999; 26: 785-790.

38 Connolly M, Marrelli A, Blades M, McCormick J, Maderna P, Godson C et al. Acute serum amyloid $A$ induces migration, angiogenesis, and inflammation in synovial cells in vitro and in a human rheumatoid arthritis/SCID mouse chimera model. J Immunol 2010; 184: 6427-6437. (c) (1) (2) (2) This work is licensed under a Creative Commons Attribution-NonCommercial-ShareAlike 4.0 International License. The images or other third party material in this article are included in the article's Creative Commons license, unless indicated otherwise in the credit line; if the material is not included under the Creative Commons license, users will need to obtain permission from the license holder to reproduce the material. To view a copy of this license, visit http:// creativecommons.org/licenses/by-nc-sa/4.0/

(C) The Author(s) 2017 